\title{
EXPERIENCING HERITAGE DYNAMIC THROUGH VISUALIZATION
}

\author{
N. Lecci ${ }^{1}$, F. Prodi ${ }^{1}$, F. Trovatelli ${ }^{1}$, A. Vezzi ${ }^{1}$ \\ ${ }^{1}$ Department of Architecture, University of Florence, Via della Mattonaia, 8 - 50121 Firenze (novella.lecci, filippo.prodi, \\ francesco.trovatelli, alessandra.vezzi)@stud.unifi.it
}

KEY WORDS: Heritage, Visualization, 3D Modelling, Video, Digital technologies, Dissemination.

\begin{abstract}
:
The present article aims to consider the added value attached to the usage of new technologies in a project aimed to study heritage. Indeed, multimedia devices could be used to create representations useful to develop and disseminate information integrating the architectural and territorial framework and to reach a general understanding.

The processed data come from a research project, based on an interdisciplinary approach, address to the study of medieval buildings in Armenia, Vayots Dzor region, with the aim of studying and understanding the cultural heritage.

Three different technologies are used to visualize and disseminate the results of the analyses carried out: the video, the hologram, and the virtual reality. These digital visualization methods enable experts to make the topics investigated accessible and comprehensible to a wider general public with a didactic and informative aim.

The solid 3D-model of the site allows to virtually reproduce the reality and to provide a spatial perception of the site. Indeed, it is a neutral base, represents the morphological conformation and settlements, a landscape whose reference points are easily identified with the historical architectures, helping the public and spectators to get oriented inside the territory. These methods of representation allow to move from general view to particular, or to a different frame appropriate to the addressed topic. Thus, it binds the scientific research with the visual part, and enable communication, even in a context where it is difficult to use a common spoken or written language.
\end{abstract}

\section{INTRODUCTION}

The use of modern and digital technologies is revolutioning traditional methods currently used for investigating of cultural and architectural heritage. At the same time, traditional methods and instruments of representation and dissemination of research results due to the progress and widespread appliance of in ICT (Information Communication Technology). Researchers are searching new methods for communicating scientific data and outputs of interdisciplinary research.

This implies the use of different software and techniques of digital data processing and research of the most suitable technologies to solve problems and develop research topics. Moreover it is possible to exploit its potential to analyze and enhance cultural heritage (Charter of London, 2008).

Three-dimensional (3D) representations, reconstructions of the studied historical structures, can be obtained through the use of photogrammetric survey techniques, verified and integrated with the direct survey. The 3D model and drawings, elaborated by metric and geometric analysis, become the basis on which the detailed analyses are developed and the hypothesis of the artifact's reconstruction.

Finally, the 3D models are used to create representations useful to communicate the results of the study and obtaining an immediate and understandable representation even to an untrained audience. They allow to maintain the reliability of the scientific data in a product simplified and suitable for dissemination, through which it is possible to manage the complexity of the interaction different levels of knowledge.

Applications of a digital representation that are addressed in the following article are video, virtual viewer, and hologram.

These digital visualization products are suitable for disseminating online or via the Virtual Reality application or on the social networks sites of the research project's website, becoming accessible data to know and discover the outputs of scientific research. They become a means of communication of the value of heritage, overcoming geographical and language barriers.

In the paper we consider an example of the potential application of digital technologies, within a joint research project, with the aim of studying and analyzing the formation of medieval landscapes and the relationship linking them with the territorial cultural heritage and the identity of resident the indigenous population (Nucciotti et al., 2015).

The data that have been elaborated, come from missions conducted in Armenia carried out between 2014 and 2018, within a project between the University of Florence and the Yerevan State University. A first phase of the project consisted in the analysis and a restricted census of the most important medieval historical architectural works of the Vayots Dzor region (ASIAC annual conference, Gorizia, 2018).

Vayots Dzor is a southeast region of present-day Armenia; the physical conformation is mainly mountainous and marked by deep valleys where the watercourses represent the territorial historical and modern backbone. By studying the architectural structures and their evolution, it has been possible to make some reflections on the territorial structure, that on the actual state and the constructive static criticalities.

The construction of the 3D model has been functional both to the analysis phase allowing constructive, static, archaeological, and geometrical analysis, the last one is useful to understand the meaning of the structures and their orientation (Aterini, 2018), that of the communication of the results elaborated and made suitable for disclosure.

\subsection{Problems and objectives}

One of the final goals that of the research project lays in raising the awareness of visitors on the distinctive character of Armenian architectural and cultural heritage. For this scope, the 
diffusion of the reflections elaborated during the research becomes fundamental. During the research work emerged many criticalities both in conducting the analyses and in the representation of the results:

1-Historical buildings are often in a state of abandonment, have undergone collapses due to strong seismic actions and even those in good condition are vulnerable to the high seismicity of the region.

2-The strong relationship between the structures and the morphological and geographic conformation, the historical and settling dynamics, lead to consider the built heritage as part of a complex system, difficult to represent.

Depending on the problems presented, a specific objective has been formulated and the most appropriate strategy to tackle it has been selected. Digital technologies have often been a means used in the decisive phase:

1-Achieving a reliable 3D model has been particularly useful for understanding the structure geometry and how the structural elements in which it can be decomposed interact.

2-The elaboration of a video that allows the passage of scale between the territorial and architectonic representation, the narration through a tour studied in order to describe the system of settlement of the medieval structures and their geometric qualities space.

In view of the target of diffusion of the search outputs, the digital visualization techniques including video, virtual reality and hologram make it possible to tell the information so that they can be understood also by a non-technical public and overcoming communication difficulties.

\section{CREATION OF 3D MODEL}

Historically, communication of architectural space has took place through two-dimensional (2D) drawings: buildings are represented by horizontal and vertical sections in the appropriate scale. This type of representation is optimal for experts, but for external individuals, it becomes more difficult to visualize the same space, architectural or territorial. Technological progress and diffusion of 3D models made it possible to immediately understand the architectural space leaving out, but not abandoning, the $2 \mathrm{D}$ representations. In the elaboration of the research data, it was decided to create an overall territorial model containing the analysed medieval historical buildings.

Two distinct models have been created: the territorial model, which describes the terrain of the Arpa valley, and the 3D models of the buildings studied.

The spatial model was elaborated starting from an "shp" file downloaded from the OpenDem portal (https://opendem.info/) containing the level curves projected on a single plane. The shapefile was imported to the QGis software and, by attributing the altitudes, was generated a first territorial representation of the Vayots Dzor (Figure 1). Finally, thanks to the contribution and collaboration of the SAGAS Florence Geography Laboratory, it was possible to insert in the file the coordinates of the architectures analysed in order to integrate the 3D models.
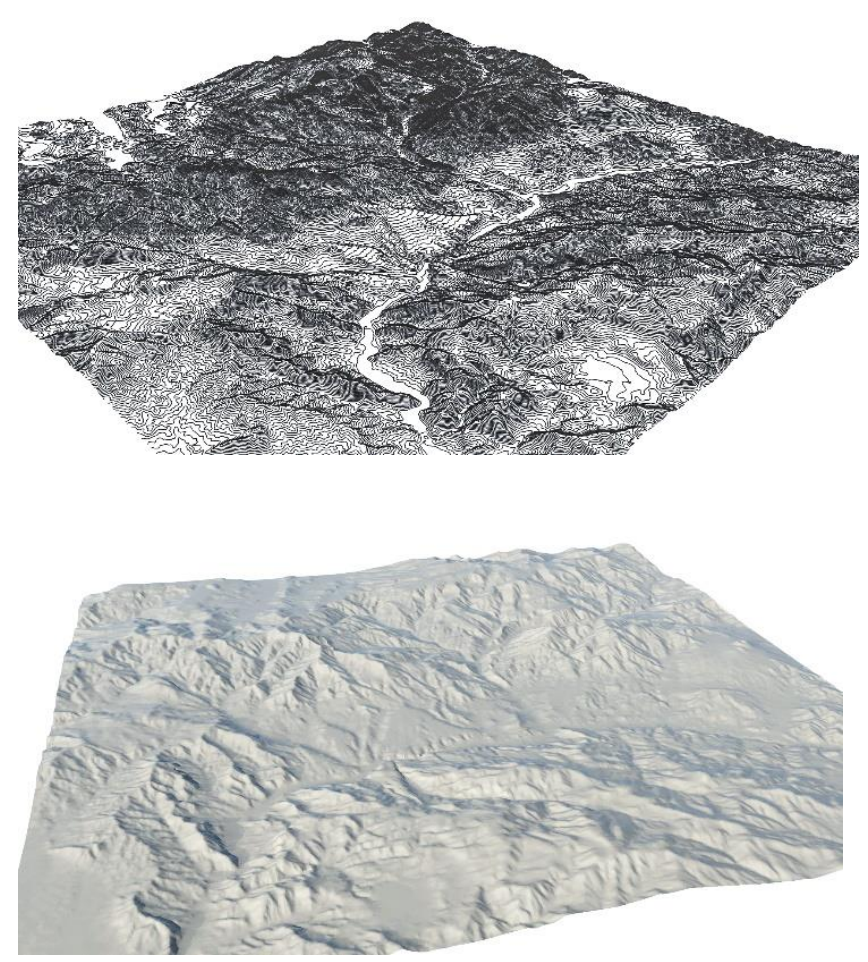

Figure 1. Representation of the spatial surface trend through level curves (upper figure) and a single surface (lower figure).

For the realization of 3D models of the analysed buildings, an integrated system between direct and indirect survey (digital photogrammetry) has been used. The choice of the techniques used was mainly influenced by the available equipment (camera and laptop), the difficulty in accessing the sites, and the limited time spent. By adopting these two systems, architectural elaborations are obtained: plants, elevations, and sections, verifiable by comparing the measurements.

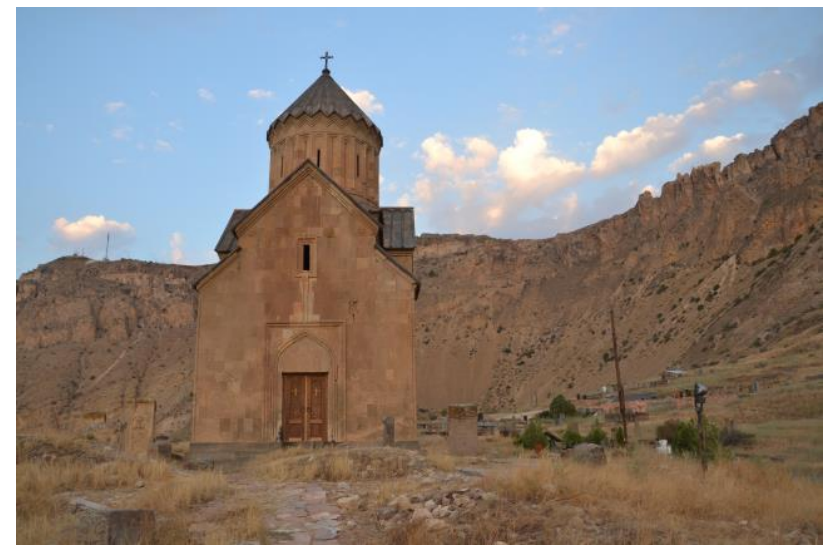

Figure 2. Church of Santasvtzazink, Areni 


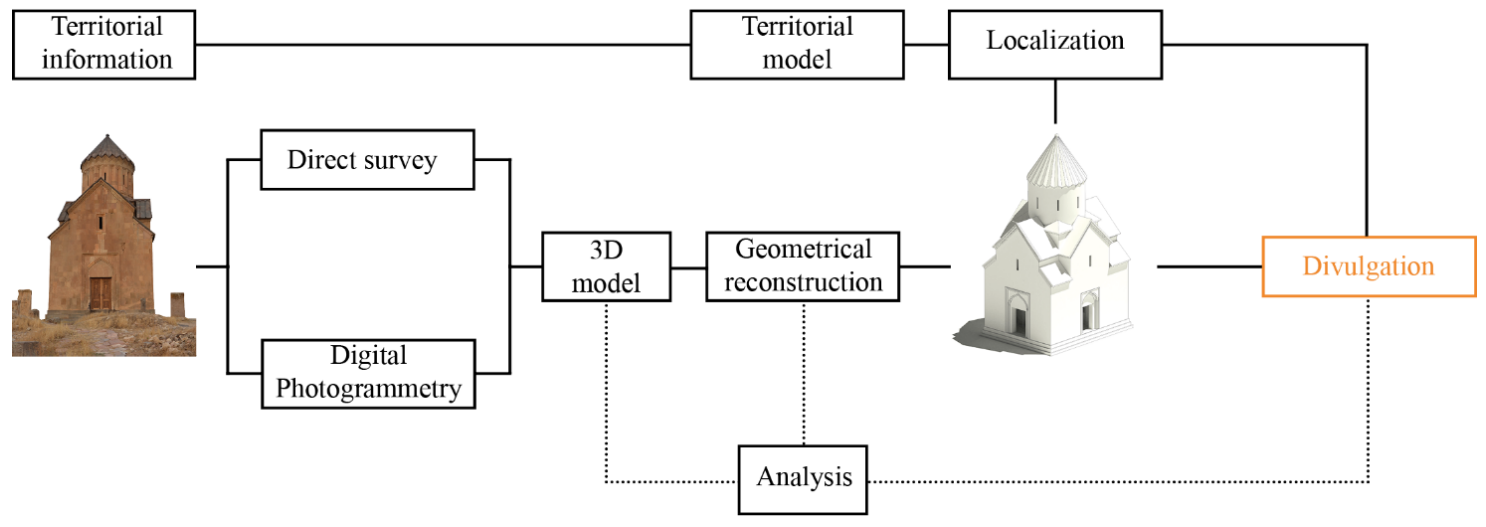

Figure 3. Conceptual scheme of the operations performed by the site to the output model

One of the buildings under study was the church of Areni (Santasvtzazink) built in 1321 by the architect Momik (Cuneo, 1988). The church stands on a plateau overlooking the river Arpa, near the village of Areni, about $2 \mathrm{~km}$ east of the border with Azerbaijan (Figure 2). During the survey operations, the laser level (Bosh pll360) and the disto laser (Leica Geosystem AG CH-9435 heerbrugg) have been used. For the photogrammetric survey project, photos were taken (camera, Nikon D530) of both the outside and the inside part of the structure, which provided the input files included in the photogrammetric software.
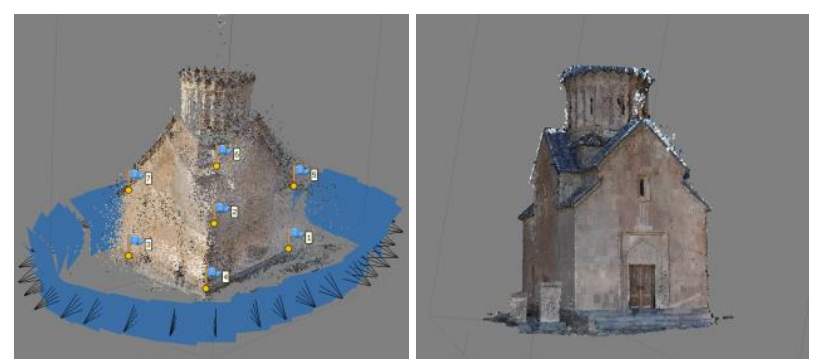

Figure 4. Align photos and markers positioning - Dense cloud
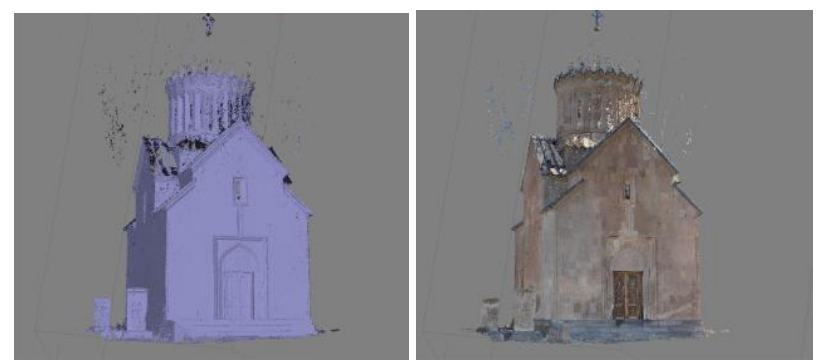

Figure 5. Mesh model - Textured model

Subsequently, the two survey systems were put into relation: the coordinates of the points identified through the direct survey have been added to the software both in the horizontal and in the vertical plane to get some verification measures. By this way, the software has scaled and oriented the point cloud. As the last step, meshes and textures have been processed (Fernández-Palacios et al., 2016). The high metric reliability of the model allows its use also for analyses that need high precision, such as seismic, geometric, compositional and structural investigations (Fortunato et al., 2017).
For the purposes of disseminating the various models through the three display systems (video, virtual reality, and hologram) the mesh model generated by the photogrammetric software is too heavy and difficult to manage. For this reason it was necessary to make a further simplification of the model. A nurbs model has been geometrically reconstructed (using a 3D modeling software) on the basis of the architectural drawings and of the model obtained through digital photogrammetry. The obtained model is lighter, more manageable and more suitable for dissemination purposes. The result obtained is a qualitative representation of the architecture that contains geometric characteristics and scientific rigor.

\section{EXPLORING THE USE OF DIGITAL VIZUALIZATION TOOLS IN HERITAGE STUDIES}

In a later stage, the research has shifted in identifying visualization systems made using the most appropriate digital techniques to describe the characteristics of heritage. The 3D model was the basic material for the development of video processing, virtual veality, and hologram.

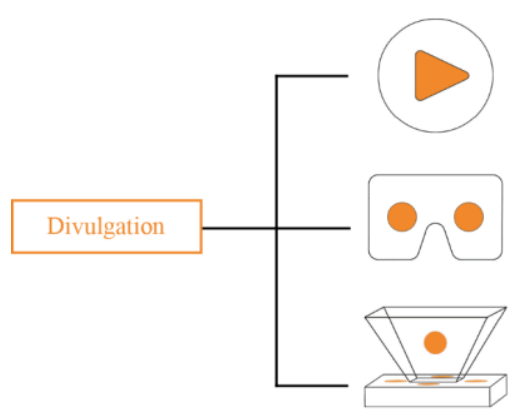

Figure 6. Conceptual scheme of use of digital visualization tools for divulgation

\subsection{Video}

The video was created by integrating the $3 \mathrm{D}$ model by adding the individual 3D models of the architectural objects to the portion of the considered territory. For technical reasons, in the rendering phase, they have been simplified and lightened. In fact, for the CPU and GPU limits of the computer, the complexity and abundance of data within the architectural model made it impossible to manage it in the general model. For this reason, it was necessary to discretize the quantity of 
data of the 3D architectural models, without compromising the quality to be divulged. Moreover, the redundancy of the data would have made it impossible to manage the files without making significant changes in the readable information for the type and scale of visualization. We can say that we need to work on the information contained in a $3 \mathrm{~d}$ model based on the purpose we want to achieve.

After having prepared the material for the realization of the video, we proceeded with the study of the scenes to visualize. Two types of room have been chosen: the first "bird's-eye" (Figure 7) to better frame the territory by perceiving the territorial structure of the Arpa's Valley, and the second "punctual" (Figure 8) to focus on every architecture studied, met along the way. A sequential montage of episodes in a coherent path simulates a real "journey" in the Armenian land that makes us discover a series of local historical architectures. The great advantage of animated communication lies precisely in the immediacy of the communication of data, able to get directly to all viewers, overflying any cultural and linguistic barriers (Velluzzi et al., 2018).

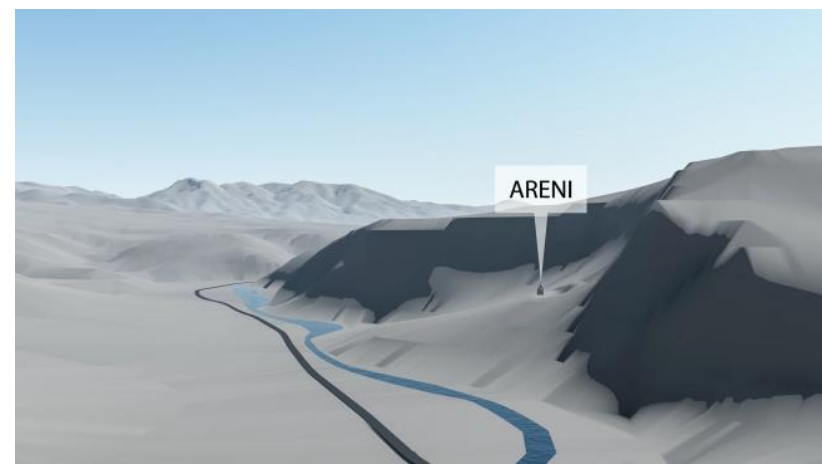

Figure 7. "Bird's-eye view" of the territorial structure of the Arpa's Valley

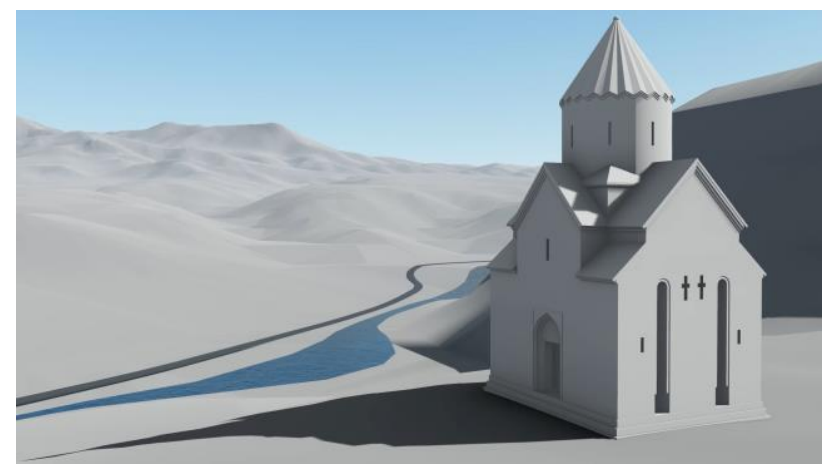

Figure 8. "Punctual view" of the Areni's Church

\subsection{Virtual Reality}

Virtual reality (VR) represents a $3 \mathrm{~d}$ space that you can explore through tools such as multimedia viewers (Samsung Gear VR). Using these devices, it is possible to interface and interact with the virtual scenarios created on a computer (Pinćjer et al., 2018). The advantage of using VR, compared to other data visualization tools, such as holograms or video representations, based on more narrative approaches, lies in the immediacy. The spectator, metaphorically projected onto the virtual reality, perceives a direct experience of it. All perceptions from the real world are eliminated, and he becomes the protagonist of the new reality displayed.
In our example through a rendering software was elaborated the internal view of the Church of Areni. With a single view, you get the complete perception of the inner spatiality of a structure with a simple volumetry (Figure 9).
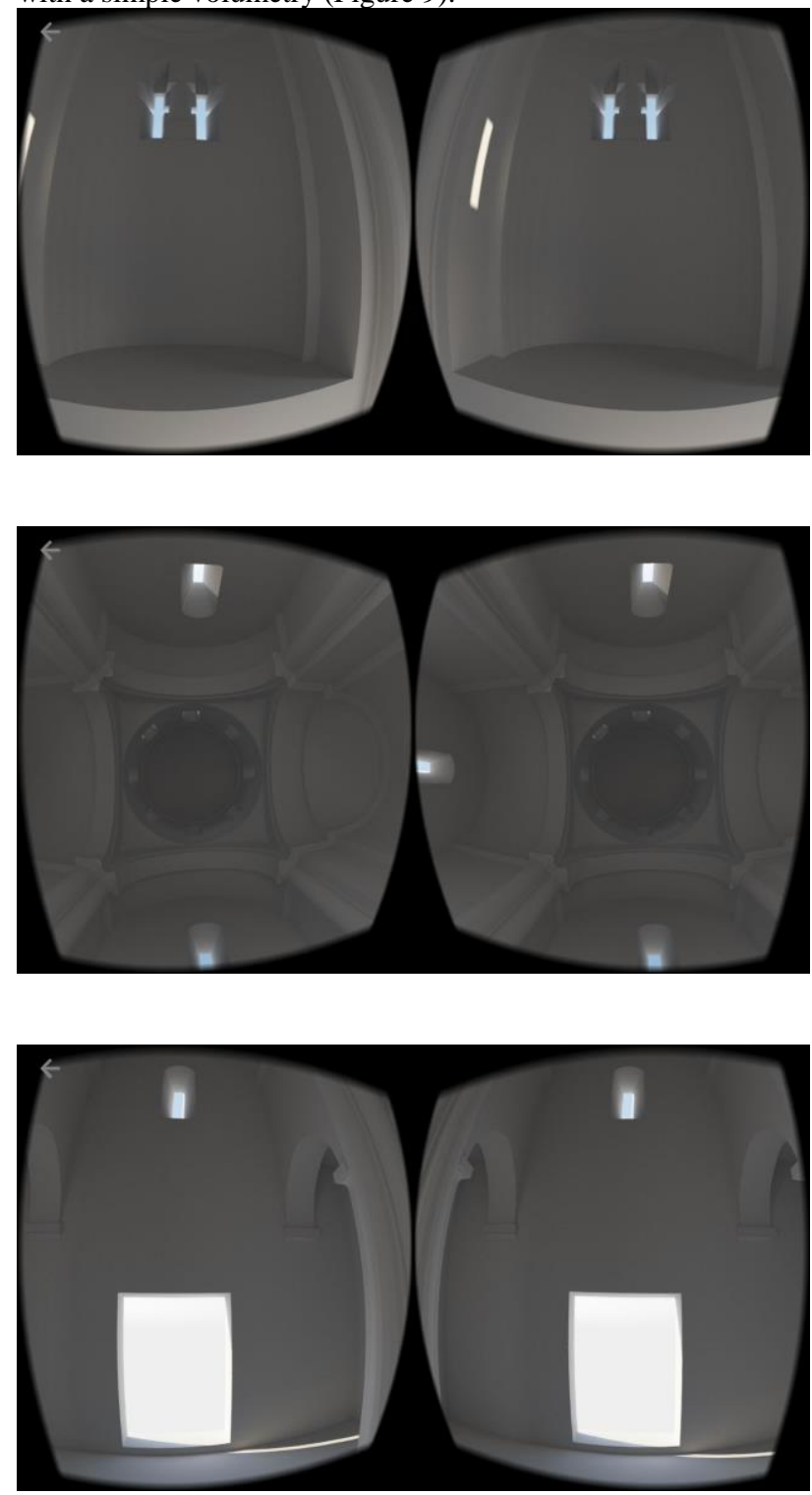

Figure 9. The VR application for the internal view of the Areni's Church

\subsection{Hologram}

The hologram is a virtual three-dimensional representation realized with the technique of holography. The holography, through the projection of images, allows to faithfully recreate a $2 \mathrm{~d}$ image of objects existing or made digitally, that appears illusionary three-dimensional (Yamanouchi et al., 2016). The process to create a simple hologram requires few elements: a plastic pyramid, a video, and digital support. The video, containing the image to be reproduced in $3 \mathrm{~d}$, is projected from the digital device display to the pyramid. This system transforms the image displayed in the video, into a threedimensional image in the middle of the pyramid. Church of Areni has been represented through a hologram. It is shown as a white model without textures: representation of an architecture of monolithic composition that, can be observed in a vision at 
$360^{\circ}$. The hologram realized with this technique is reproducible on any smartphone or tablet. One of its advantages is that it's an economical solution and allows an easy diffusion and accessibility.
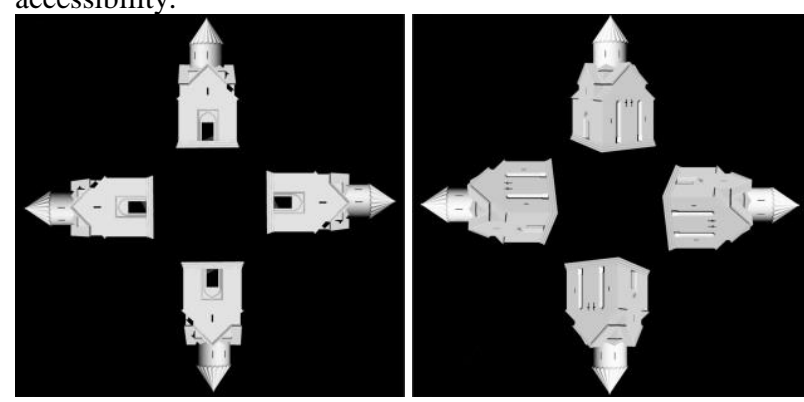

Figure 10. Areni's Church, front view video frame and Axonometric view video frame

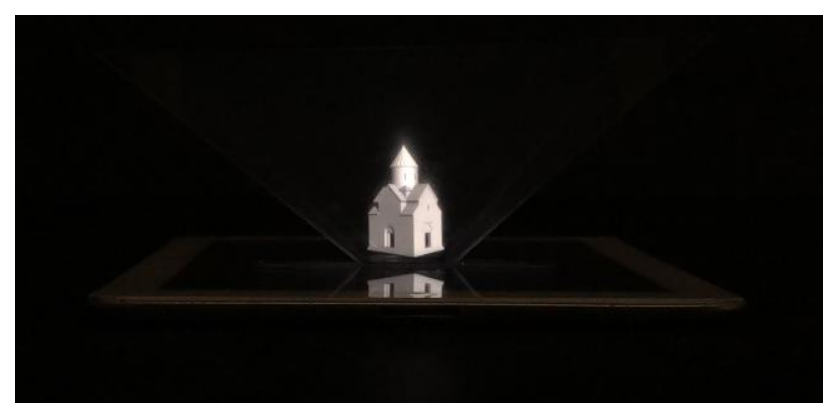

Figure 11. Areni's Church, hologram 3D view

\section{CONCLUSIONS}

In the entire research process, technological and digital tools help to overcome obstacles that might arise, allowing a smooth implementation of strategies and to achieve the goals set. The $3 \mathrm{D}$ representation has a role both for analysis and communication and dissemination. To this aim, three visualization methods are illustrated. Each one presents the research results highlighting different aspects of the study object: in the video the visit is guided by an external narrator, an animation describes the organization of the settlement system, the relationship between territorial and architectural system; in the Virtual Reality the point of view depends exclusively on the observer, who is lowered in the digitally reconstructed scenario; the hologram shows a visualization of architectural objects, their geometrical characteristics.

The added value of visualization technologies in heritage studies lays in the fact that the former represents a universal communication language and at the same time a potential didactic tool, not only informative. Indeed, digital format would allow experts to elaborate many forms of representation able to involve the observer in the experience and convey to them proper knowledge on the topic through a proactive and userfriendly approach.

\section{REFERENCES}

The London Charter for the computer-based visualisation of cultural heritage, 2008

Nucciotti, M., Petrosyan, H., Luschi, C., Cheli, F., De Falco, M., Somigli, L., Vardanesova, T., 2015. The Making of the Silk Road in Armenia (C7th-C14th): Vaiots Dzor and Arates Monastery. In Proceedings of VII Congresso Nazionale di
Archeologia Medievale (pp. 493-498). Lecce, Italy: All'Insegna Del Giglio Editore.

ASIAC annual conference 2018, Gorizia 5-7 Dicember 2018 University of Trieste/Gorizia Campus. Dinamiche insediative e costruzione del paesaggio nella valle dell'Arpa (Vayotz Dzor) tra VIII e XIX secolo. Gestione e controllo del territorio sull'asse nord-sud per la Via della Seta.

Aterini, B., 2018. A camera obscura sundial: S.Astvazazin church in Areni, Armenia. SCIentific RESearch and Information Technology. Vol 8, Issue 2.

Cuneo, P., 1988, Architettura Armena, De Luca Editore, Roma.

Fernández-Palacios, B.J., Morabito, D., Remondino, F., 2016. Access to complex reality-based $3 D$ models using virtual reality solutions. Journal of Cultural Heritage.

Fortunato, G., Funari, M.F., Lonetti, P., 2017. Survey and seismic vulnerability assessment of the Baptistery of SanGiovanni in Tumba (Italy). Journal of Cultural Heritage.

Velluzzi, N., Rossi M., Buratti G., 2018. The Video Animation: An Innovative Way to Communicate. Computational Morphologies, Design Rules Between Organic Models and Responsive Architecture, Springer.

Pinćjer, I., Milić, N., Puškarević, I., Miketić, N., 2018. Conversion of virtual reality into a mixed reality. University of Novi Sad, Faculty of Technical Sciences, Department of Graphic Engineering and Design, Novi Sad, Serbia.

Yamanouchi, T., Maki, N., Yanaka, K., 2016. Holographic Pyramid Using Integral Photography. Kanagawa Institute of Technology. Proceedings of the $2^{\text {nd }}$ World Congress on Electrical Engineering and Computer System and Science. 